Res Publica Revista de Historia de las Ideas Políticas

ISSN: 1131-558X

\title{
Leandro Losada, Maquiavelo en la Argentina. Usos y lecturas, 1830-1940, Buenos Aires,
} Katz, 2019, 195 pp.

Si bien es cierto que, acerca de la recepción del pensamiento de Niccolò Machiavelli (1469-1527) en diferentes contextos históricos y geográficos se han escrito numerosos e importantes estudios, la recepción su obra en la Argentina, en cambio, parece haber pasado bastante desapercibida o no haber despertado un gran interés entre los estudiosos de la obra política de Maquiavelo. Frente a este panorama, son excelentes noticas que Leandro Losada en Maquiavelo en la Argentina. Usos y lecturas, 1830-1940, no sólo pretenda llenar este vacío, sino que además busque ofrecer una explicación de los motivos que habrían llevado a destacados personajes de la política y del mundo académico argentino a optar por una visión -que no siempre ha sido del todo favorable- del pensamiento del florentino. A tal efecto, y con la intención de "atender las lecturas" de la obra del Maquiavelo, "las invocaciones de su nombre, los motivos y los momentos en que se apeló a sus ideas y argumentos" (p. 11), el objetivo central que Losada se pone como meta es bastante claro: se trata de vincular las sinuosas interpretaciones de Maquiavelo en Argentina con los diferentes contextos históricos que van del 1830 al 1940. Con lo cual, la tesis central de Losada se compromete con la idea según la cual existe un vínculo directo o, al menos, bastante estrecho entre el atractivo o la repulsión del pensamiento de Maquiavelo y las distintas circunstancias políticas que afrontó la Argentina casi desde sus orígenes hasta mediados del siglo pasado (pp. 41 y 61). Nexo que, por otra parte, sería relevante a la hora de estudiar o comprender la deriva del pensamiento político de Maquiavelo en el contexto argentino. Ahora bien, si este fuera el caso, el déficit o los aciertos interpretativos de buena parte de los intelectuales argentinos se deberían más a las exigencias o determinaciones históricas que a su capacidad intelectual para captar el valor de la obra de Maquiavelo. Después de todo, si es el contexto el que habría inspirado y determinado ciertas conclusiones o usos del pensamiento de Maquiavelo, el margen que resta para la inspiración personal es escaso o, en el mejor de los casos, directamente está al servicio de los eventos históricos. Con lo cual, una conclusión que parece casi inevitable es que, de ser el contexto histórico el factor determinante a la hora de interpretar o emplear el pensamiento de un autor determinado, el acierto o desacierto de los interpretes o usuarios queda sujeto a este factor y no a sus capacidades intelectuales para apreciar el valor del pensamiento del autor en cuestión. Lo que podría llevar a la conclusión de que atados por las necesidades de una determinada época, ninguno de los interpretes o usuarios del pensamiento de Maquiavelo en el contexto argentino fue capaz de poner en duda ciertas afirmaciones hechas hasta el momento sobre Maquiavelo ni de apropiarse de su pensamiento impulsados por su curiosidad intelectual. Algo que, por lo demás, antes que alabar la capacidad intelectual de cualquiera que se jacte de ser tal, más bien, la desprestigia. Por otra parte, tales determinaciones históricas pueden llevar a la comisión de uno de los pecados capitales en el que jamás debería caer un académico, a saber, el anacronismo o, en otras palabras, el empleo de un pensamiento del pasado como si este fuera un pensamiento que trata sobre el presente. Por desgracia, Losada descuida esta serie de implicaciones de su tesis y, en consecuencia, no ahonda demasiado en este punto ni explota esta idea en el desarrollo de su estudio de la recepción argentina de Maquiavelo. En consecuencia, si bien acierta y deja bien en claro que la determinación histórica tuvo un rol importante en la así llamada generación del 37, sin embargo, descuida que, en otros casos que él mismo menciona, esta tesis parecería no aplicarse del todo, tal y como podremos apreciar en breve.

Luego de una "Introducción" (pp. 9-15) dedicada a presentar sea el argumento central del libro como los objetivos perseguidos (pp. 12 y 14) y un resumen del contenido de cada capítulo (pp. 14-15), Losada abre paso al primer capítulo titulado, "Maquiavelo, del repudio a la vigencia (1830-1910)" (pp. 17-62). A este punto, se abre la explicación de las interpretaciones tempranas de Maquiavelo que hiciera la generación del 37 y como es de esperar una exposición de los motivos que condujeron a que Maquiavelo fuera "asociado más al pasado y a la opresión que al presente, el futuro y la libertad" (p. 23). A tal efecto, en la primera parte de este capítulo esta destinada a poner la atención, fundamentalmente, en las críticas de Domingo Faustino Sarmiento y Juan Bautista Alberdi y en un número de interpretaciones de Maquiavelo que, en mayor o menor medida, acompañarían las conclusiones condenatorias de los primeros. Ahora bien, como muy bien sostiene Losada los motivos que habrían dado a lugar a que dichas interpretaciones fueran desfa- 
vorables respecto Maquiavelo se remontan al siglo XVI, época en la cual se gestará la archiconocida interpretación que bajo el nombre de "maquiavelismo" atribuía o vinculaba al pensamiento de Maquiavelo con una serie de conductas de un evidente carácter inmoral (pp. 18 y 23). Motivos que provocaron, en la primera oleada de políticos e intelectuales rioplatenses, que "Maquiavelo no fuese valorado" positivamente y fuera más bien asociado con una "reivindicación de la tiranía, o en el mejor de los casos, al estudio del poder (...) pernicioso para la libertad" (pp. 17, 51 y 59). Según Losada, además, se trataría de un conjunto de interpretaciones que, por la influencia de las exégesis predominantes en España, son poco innovadoras y propensas a hacer ocupar el "maquiavelismo" el lugar que le correspondería al pensamiento de Maquiavelo. Ahora bien, la censura de Maquiavelo propia del contexto español (pp. 21, 58 y 59) también sería un factor relevante para explicar las interpretaciones desfavorables de los autores rioplatenses, ya que la falta de acceso a su obra habría impedido que los intelectuales pudieran enfrentarse vis-à-vis con el pensamiento político del florentino. Sin embargo, esta última observación, entraría en contradicción con algunas de las afirmaciones hechas por Losada. En efecto, como él mismo sugiere, algunos autores del contexto rioplatense de los primeros años del 1800 habrían leído de Maquiavelo ya sea El Príncipe como los Discursos. De hecho, se hace referencia a Rivera Indarte (pp. 27-28 y 31) como lector del Príncipe o se "sugiere una relectura de El príncipe o una alusión velada a otras de sus obras, en especial a los Discursos" por parte de Alberdi (p. 37). Luego de un breve repaso de lo dicho en el primer capitulo, Losada da un salto de diez años -sin explicar cuál sería el motivo para dejar fuera de consideración dicha década-y de 1910 pasa directamente al segundo capítulo, en el que se interesa por el estudio de "Maquiavelo y el antiliberalismo (1920-1940)" (pp. 63-117). Desde la primera página de este apartado queda muy en claro que desde la década del 20' del siglo pasado, hubo un cambio sustancial en los estudios argentinos sobre Maquiavelo, los que asumieron un tono declaradamente académico (pp. 66 y 67). Maquiavelo, se convirtió en objeto de crítica y controversia, en una polémica que involucro tanto a "liberales" como "críticos del liberalismo" (p. 63) y cuyo germen floreció en el contexto universitario de la segunda mitad del siglo XIX y comienzos de siglo XX (pp. 64-65 y 147). Dichos cambios de actitud, por otra parte, dejan en claro un contraste entre la primera mitad del siglo XIX y los primeros años del 1800. En efecto, en dicha época se volvió una excepción el uso del "maquiavelismo" a la hora de denostar y criticar rivales políticos, volviéndose la regla la preferencia por el estudio de la obra de Maquiavelo (p. 65). Características que, además, revelan un contraste respecto al perfil de la generación del 37, ya que, Maquiavelo dejaría de ser un pensador obsoleto, "sobrestimado" (pp. 18, 32, 38, 69 y 114) o inactual, para cobrar vigencia al momento de pensar los cambios políticos de la época (pp. 60 y 67). Después de trazar un parangón con las actitudes tomadas por los intelectuales alemanes de la época de la República de Weimar, se retoma la senda de la deriva del pensamiento de Maquiavelo en la Argentina observando que las "modulaciones particulares, propias de las singularidades que recorrieron la crisis y la inestabilidad de la política argentina del período" fueron "diagnósticos y preocupaciones semejantes" a las del periodo de Weimar y a su vez "entramaron los acercamientos argentinos a Maquiavelo en las décadas de 1920 a 1940" (p. 69). De este modo, hace eco una vez mas su tesis de fondo de Losada, la que explicaría que las lecturas y usos de Maquiavelo en la Argentina, estarían estrechamente vinculas a determinaciones históricas y que el intelecto de los académicos estaría a su servicio (p. 69). La situación histórica, entonces, desatará un debate entre "críticos del liberalismo" y los "liberales", los que en consecuencia verían en el pensamiento de Maquiavelo o un perfil republicano o una afinidad al totalitarismo o el fascismo. A los fines de analizar en detalle estas tendencias, Losada agrupa bajo el subtitulo "Maquiavelo y el fascismo" (pp. 70-88) los estudios y críticas que conectan al pensamiento de Maquiavelo con el "realismo político", mientras que bajo el subtitulo "Maquiavelo y el nacionalismo" (pp. 88-115) revisa la exaltación o crítica nacionalista argentina del florentino. Sobre las observaciones que Losada realiza en este apartado, vale la pena llamar la atención sobre un descuido que comete al observar que Mussolini recibió un "titulo" honoris causa por la Universidad de Bolonia en 1924. Dicha alusión se refiere de un escrito titulado "Preludio al Machiavelli" que el Duce efectivamente habría escrito. Sin embargo, Losada se descuida - entre otras cosas- que, por un lado, Mussolini jamás recibió lo que en realidad se trataba de un doctorado honoris causa y, por el otro, que Mussolini habría escrito el "Preludio al Machiavelli" sin que este fuera exigido para la concesión de dicho doctorado.

En el tercer capítulo, titulado: "Maquiavelo, entre el realismo político y la libertad (1920-1940)" (pp. 117179), nuevamente, sale a la luz la tesis propuesta por Losada según la cual los estudios argentinos se aproximaron a Maquiavelo para reivindicarlo "por ofrecer herramientas indispensables para pensar tiempos inciertos y turbulentos, y por haber legado una obra cuyo principio sustantivo era, según algunas voces, la libertad" (p. 119). Este capítulo se trata de una ampliación de lo visto en el capítulo precedente, aunque con un particular énfasis en el debate entre "liberales" y "antiliberales" argentinos. Es un apartado donde se recogen las observaciones hechas precedentemente para ampliarlas aun más. Por lo tanto, se trata de un apartado que no tiene un valor en sí mismo, sino a la luz de las consideraciones hechas en los dos capítulos precedentes. Más allá de esto, nuevamente tiene lugar una observación que podría poner en duda la tesis acerca del modo en el que contexto histórico habría afectado la manera en que los autores argentinos se aproximaron al pensamiento de Maquiavelo. En efecto, cuando se afirma que "la forma en que se entendió la epistemología y la caracterización de la política de Maquiavelo se conectó con el retrato doctrinario de" las ideas de los autores sometidos a examen (p. 128) se sugiere que fueron los mismos prejuicios doctrinarios los que llevaron a interpretar a Maquiavelo de un determinado 
modo y no exclusivamente cierto condicionamiento histórico. Por otra parte, vale la pena observar que en el segundo y tercer capítulo en las reiteradas alusiones al "liberalismo", "antiliberalismo" o a los "críticos del liberalismo" (pp. 63, 69, 80 y 116) no se especifica en qué sentido se refiere a los mismos o qué se entiende por los mismos. Una aclaración que es relevante para la tradición del pensamiento político argentino, sobre todo, por las controversias que giran en torno a tales rótulos. Por lo demás siendo el autor un reconocido historiador y especialista en la tradición histórico-conceptual argentina, estas son observaciones que podría haberlas tenido en cuenta. Finalmente, el estudio de la deriva del pensamiento de Maquiavelo en la Argentina se cierra con sus respectivas "Conclusiones" (pp. 181193). A este punto, Losada revela que, a lo largo de su estudio, no fue su intención "realizar un seguimiento de la recepción" de Maquiavelo en la Argentina que se pusiera en relación con "las lecturas ocurridas en otros contextos y geografías" ni "se ha procurado (...) testear la idoneidad o rigurosidad de las lecturas locales" (p. 181). Sin embargo, irónicamente, se observa a continuación que la recepción argentina "no tuvo una larga tradición ni una erudición profunda si se la compara con la prevaleciente en otras latitudes" (p. 182).

En cuanto a las observaciones formales, el libro por desgracia no ofrece ni un índice analítico ni un elenco bibliográfico final, algo que, eventualmente y en futuras ediciones seria propicio que la casa editorial y el autor tengan en cuenta. Después de todo, se trata de dos aspectos que serian de cierto valor para que el lector pueda localizar ciertas menciones y alusiones conceptuales o consultar la bibliografía empleada por el autor. En líneas generales, Maquiavelo en la Argentina. Usos y lecturas, 1830-1940 es un libro sumamente informativo, aunque a veces, reiterativo en sus observaciones y comparaciones entre los períodos estudiados. Una de sus virtudes es que, precisamente, dichas reiteraciones dejan muy en claro los contrastes entre los periodos estudiados y sobre todo los altos y bajos de la aproximación a la obra y pensamiento de Maquiavelo en la Argentina. Es un libro que debe ser juzgado por su análisis histórico y no filosófico político. Ya que, de no ser así, podría ser juzgado como un estudio histórico que de a momentos parecería una mera colección de citas ordenadas de manera coherentemente de personajes emblemáticos de la academia y la política argentina. Citaciones que, por otra parte, si bien son aclaradas antes o después, en algunos casos no amplían demasiado el contenido de los pasajes citados. Algo que no sucede, en cambio, con las aclaraciones históricas que rodean a las menciones de Maquiavelo hechas por reconocidos personajes de la política y la academia argentina, las que en el mayor de los casos son relevantes y a quien no fuera versado en la historia argentina pueden ser buenos indicios para emprender un estudio mas profundo. En pocas palabras, el libro de Losada, por el tema tratado es sumamente innovador y, por ello, merece la atención de los estudiosos preocupados por la recepción de Maquiavelo en diferentes contextos históricos y geográficos. Sin embargo, en cuanto al análisis del pensamiento de quienes fueran los protagonistas de la recepción de Maquiavelo en la Argentina, el libro carece de un estudio profundo que amplié el contenido mediante una evaluación de las implicancias de las numerosas citas tratadas. Algo que, por otra parte, si bien en términos filosóficos políticos disminuye el valor del libro, irónicamente, debería aumentar el interés por los usos y lecturas de Maquiavelo en la Argentina. Después de todo, lo que podría llegar a ser una falencia del libro, debería ser un aliento para los especialistas del pensamiento político de Maquiavelo, ya que, el estudio de Losada les allana buena parte del camino y les revela que aún queda mucho por decir sobre la recepción de Maquiavelo en la Argentina.

Augusto Dolfo 